\title{
On believing indirectly for practical reasons
}

\author{
Sebastian Schmidt ${ }^{1}$
}

Accepted: 29 August 2021/Published online: 22 September 2021

(C) The Author(s) 2021

\begin{abstract}
It is often argued that there are no practical reasons for belief because we could not believe for such reasons. A recent reply by pragmatists is that we can often believe for practical reasons because we can often cause our beliefs for practical reasons. This paper reveals the limits of this recently popular strategy for defending pragmatism, and thereby reshapes the dialectical options for pragmatism. I argue that the strategy presupposes that reasons for being in non-intentional states are not reducible to reasons to act. Pragmatists who want to preserve a motivational constraint on reasons therefore have exactly two options: either arguing that there are irreducible reasons for being in non-intentional states (new pragmatism); or arguing that we can believe directly for practical reasons (traditional pragmatism). I argue that the prospects for the former option are dim because irreducible reasons to be in states are hard to square with the motivational constraint on reasons. Returning to the more traditional route of arguing for pragmatism by defending a version of doxastic voluntarism therefore seems to be the more promising way for pragmatists to go.
\end{abstract}

Keywords Ethics of belief · Pragmatism - Evidentialism - Practical reasons for belief $\cdot$ Indirect control $\cdot$ Doxastic voluntarism

Sebastian Schmidt

sebastian.schmidt@philos.uzh.ch

1 University of Zurich (Switzerland), UZH, Philosophisches Seminar, Zürichbergstrasse 43,

Room G-228, 8044 Zürich, Switzerland 


\section{Introduction}

Pragmatism is the claim that there are practical reasons for belief-i.e., reasons for belief that are provided by the practical (prudential or moral) value of having the belief. Evidentialists deny that the practical value of having a belief can provide us with a normative reason for this belief. They usually do so on the grounds that considerations about practical value cannot be motivating reasons for belief: it seems that one cannot believe that one will recover from one's severe illness for the reason that having this belief would make one more likely to survive. ${ }^{1}$ Evidentialists who pursue this line of argument claim that we can only believe for reasons that bear on the truth of the belief, and that therefore only evidence can provide us with a genuine normative reason for belief. ${ }^{2}$ Pragmatists reply that, at least sometimes, we can believe for practical reasons. ${ }^{3}$

Note that the dispute between evidentialism and pragmatism is not about our actual psychology. Without any doubt, there are advantageous but epistemically not fully rational beliefs. Think about over-optimistic beliefs about our own capabilities, ${ }^{4}$ over-beneficial beliefs about significant others, ${ }^{5}$ or evidentially unsupported beliefs about religious matters. ${ }^{6}$ Evidentialists do not deny that such beliefs contribute to a beneficial make-up of our psychology, or even to a better life in general. Neither do they deny that practical considerations influence and cause our beliefs in ways that can be beneficial to us, and that such considerations can thus be part of an explanation why someone has a belief (say, in cases of wishful thinking).

\footnotetext{
1 I follow Rinard (2019b) and Leary (2017) in putting the evidentialists' constraint on what can count as a reason for belief in terms of motivation. Another way to put the constraint is in terms of guidance (cf. Way \& Whiting 2016).

2 See Hieronymi (2005, 2006, 2008, 2009) and Shah (2003, 2006). Reisner (2018) calls these 'new style arguments' for evidentialism. He distinguishes them from mostly earlier ones that merely appeal to doxastic involuntarism - the claim that we lack direct voluntary control over belief - and 'ought implies can' (cf. Adler, 2002; Alston, 1988; Hookway, 2002; Kelly, 2002; Parfit, 2011, Appendix A; Pojman, 1985). The 'new style arguments' can be viewed as advancements on the earlier ones, for they share the same spirit.

3 We can distinguish between moderate pragmatism and radical pragmatism. Leary (2017), McCormick (2015, 2018), and Reisner $(2008,2009,2018)$ are moderate pragmatists: they argue that at least some reasons for belief are practical. Rinard (2015, 2017, 2019a, b) is radical: she argues that evidence does not provide us with reasons at all, and that thus only practical reasons are reasons for belief. Meiland (1980) already defended a similarly radical view. Stich (1990) is also close to Rinard's view, although he is not so much concerned with what we have reason to believe, but rather with the evaluation of cognitive processes. Harman (1999) and Feldman (2000, esp. 691-694) are earlier proponents of the moderate view. Thanks to an anonymous referee for drawing my attention to Stich and Harman.

${ }^{4}$ Hazlett $(2013,44-52)$ cites studies which suggest that overestimating one's capabilities can promote one's wellbeing.

5 See McCormick (2015, 60-61), who is following Stroud (2006). However, see Crawford's (2020) argument that close relationships do not require unresponsiveness to the evidence, even if pragmatism was true.

6 See McCormick (2015, 61-65). The classical point of reference for the idea that we should believe in God even in the absence of sufficient evidence is Pascal (1670). See also James (1896).
} 
What evidentialists deny, rather, is that practical considerations can ever function as reasons for belief. ${ }^{7}$

Evidentialists agree with pragmatists that practical considerations can serve as reasons for actions: they agree that the fact that having an over-optimistic belief about your own chances of recovery could give you a reason to bring about or to cultivate such a belief-say, by not listening to the doctors and instead reading optimistic stories about recovery. ${ }^{8}$ What evidentialists deny is that the practical benefit of having a certain belief can provide you with a reason to believe that you have more chances to recover than your evidence indicates. That is, evidentialists argue that pragmatists fail to respect a distinction between reasons for actions and reasons for belief. ${ }^{9}$

The new pragmatists, as I call them here, ${ }^{10}$ argue that this distinction does not fare well with our intuitive judgments about reasons for anything we do indirectly. For instance, we can be said to write a book for the reason that writing gives us pleasure, although we cannot write a book just like that-i.e., without performing more basic actions. The new pragmatists argue, by analogy, that we can sometimes be said to believe for practical reasons even though we do something else in order to adopt the relevant belief. Put succinctly: indirect motivation is sufficient for believing for practical reasons. Denying this, so the new pragmatists argue, would force us to "say that, in general, we do not have motivating reasons for anything we do indirectly' (Rinard, 2019b, 775). ${ }^{11}$

I will examine this line of argument and discuss its limits. I argue that it does not support pragmatism unless we assume that there are irreducible reasons to be in non-intentional states-like the state of being outside or having short hair. I do so

\footnotetext{
${ }^{7}$ Nor must evidentialists deny that pragmatic factors influence what is rational to believe. According to what is described as 'pragmatic encroachment' in epistemology (cf. Kim and McGrath, 2019 for a recent volume), the evidential threshold that is required to epistemically justify a belief depends on the practical stakes at play if one is wrong. These stakes, however, do not qualify as reasons for which we believe. Cf. Crawford's $(2020,92)$ distinction between two kinds of doxastic partialism that rests on this distinction. However, cf. Worsnip (2020) for a recent argument why pragmatic encroachment implies pragmatism. I need not decide this dispute here.

${ }^{8}$ Following Flowerree (2020), we can distinguish between truth-oriented belief-management (like impartial inquiry, investigation, deliberation, or reasoning) and belief-management that aims at having a practically valuable belief independently of whether it is true (avoiding challenging information, omitting deliberation, active self-deception, staying in one's social 'bubble', etc.). It is important to note this distinction in order to see the multifarious activities that 'causing' or 'maintaining' a belief can amount to. But the distinction is not central to my argument here.

${ }^{9}$ In some cases, a reason for an action might also be evidence for the truth of the belief that the action brings about. The fact that I promised to help you can be a reason for me to help you and evidence that I will help you (if I am a reliable person). However, according to evidentialism, the practical reason here is not a reason for belief in virtue of the fact that it shows that the belief is valuable; rather, it is a reason for belief in virtue of the fact that it constitutes evidence for the belief, i.e., indicates the truth of the belief.

${ }^{10}$ This is an allusion to Rinard (2015) who calls the evidentialists mentioned in note 2 who appeal to a motivational constraint on reasons 'new evidentialists' (cf. esp. Shah, 2006).

${ }^{11}$ For the most explicit recent statements of this strategy, cf. Leary (2017, 537-540), McCormick (2018, 641), Reisner (2009, 269-270; 2018, 722), Rinard (2015, 2019a, 1939-1944, 2019b, 775). Of course, this is not the only argument for pragmatism presented by these authors, but it is one popular line that merits explicit discussion.
} 
by showing that the argument is best understood as drawing an analogy between belief and non-intentional states, and as then arguing that since there can be practical reasons for the latter, there must also be practical reasons for the former. Evidentialists are fine with the existence of practical 'state-reasons' for belief-as I will call them - if such reasons are just reducible to reasons to act. For instance, saying that you have a reason to have short hair would, according to the evidentialist's analysis, merely amount to saying that you have a reason to get your hair cut. Analogously, any state-reason to believe that $\mathrm{p}$ would just be a reason to bring the belief about, or to maintain it. That is, talk about such practical reasons for belief would be merely an elliptical reference to reasons for actions. The new pragmatists have to deny this intuitively attractive analysis of state-reasons. ${ }^{12}$

I furthermore argue that denying the evidentialist's analysis of state-reasons is hard to maintain as long as one accepts a version of the

motivational constraint on reasons: A consideration $\mathrm{R}$ is a reason for a person $\mathrm{S}$ to give a response $\varphi$ only if $\mathrm{S}$ can $\varphi$ for $\mathrm{R}$.

I do not defend the constraint here, but merely consider whether the new pragmatists are successful in arguing that practical reasons can satisfy it. ${ }^{13}$ Pragmatists who argue that practical considerations meet the constraint have precisely two options. They can either argue that practical considerations can indirectly motivate beliefi.e., that we can sometimes bring about or maintain a belief for practical reasons; or else that practical considerations can directly motivate belief-i.e., that we can sometimes just believe directly on the basis of a practical consideration without first having to perform any actions. Since I argue that the first strategy presupposes that state-reasons are not reducible to reasons to act, my argument will leave pragmatists with precisely two ways to defend the claim that practical reasons for belief could meet the motivational constraint:

(i) Either they argue that state-reasons for belief are not reducible to reasons to act (or to try, intend, desire);

(ii) or they argue that we can sometimes believe directly for practical reasons.

\footnotetext{
12 Parfit (2011, 51, Appendix A), who accepts such a reductive analysis of state-reasons, points out that state-reasons might additionally be reasons to desire the state. Evidentialists of course do not deny that we can, for instance, rationally desire to believe in God because of the benefits of this doxastic state. I tend to agree with Berker (2018, 461-467), however, that practical reasons for belief cannot be analyzed as reasons to desire. Reasons to try, intend, or desire to be in a state will play a role in my argument in Sect. 6, however, where I formulate a challenge for new pragmatism.

13 This focus is justified given that my discussion is about the argument brought forward by the pragmatists in note 11 -an argument that is meant to show that we can believe for practical reasons. Next to Shah's and Hieronymi's arguments that rely on such a constraint (cf. note 2 above), cf. Way and Whiting (2016)'s discussion of the constraint. They reply to arguments against it, brought forward especially by Schroeder $(2007,165-166)$, that are based on massively outweighed reasons or on selfeffacing reasons (like your reason to go to your surprise party). In response to these arguments, Way and Whiting argue that the constraint only implies the 'general capacity' to comply with a reason. Note also that Schroeder (2021) accepts that one 'earmark' of normative reasons is that they can be 'acted on'-i.e., that they can be proper bases for responses. I return to the constraint in more detail in Sect. 6.
} 
I turn to the notion of a 'state-reason' at the end of Sect. 3, and I discuss it in more detail in Sect. 6 (where I also explain the brackets at the end of (i)). If I am right, then the dialectic between evidentialism and pragmatism presents itself in an interesting shape. Endorsing either (i) or (ii) is sufficient for pragmatism. Evidentialists therefore have to deny both (i) and (ii). Of course, pragmatists could also reject the motivational constraint on reasons. ${ }^{14} \mathrm{I}$ will not engage with this strategy here. Rather, my argument addresses the debate between evidentialists and pragmatists insofar as it concerns the question of whether there are genuine practical reasons for belief that meet the motivational constraint.

Section 2 presents two recent arguments by pragmatists, the argument from causation and the argument from indirect motivation. I show that the former hinges on the latter. Sections 3 and 4 argue that these arguments establish that there are practical reasons for belief in the same sense as there can be practical reasons for being in non-intentional states-what I call 'state-reasons'. Evidentialists therefore must argue that such reasons are reducible to reasons to act, rather than denying the existence of state-reasons. Section 5 presents the two dialectical options for pragmatists (i) and (ii) in more detail. Section 6 argues that if pragmatists accept the motivational constraint on reasons, the prospects for (i) are dim. I conclude that it might therefore be more promising for pragmatists to defend (ii) — the possibility of (in a sense) believing at will.

\section{Mere causation and indirect motivation}

In her recent article, Rinard (2019b, 769-778) argues for pragmatism by appeal to cases in which evidence merely causes us to have a belief but does not function as a reason for which we believe. She argues that, if such cases are conceivable, then we can also conceive of cases in which we have reasons to put ourselves into a position in which the evidence then merely causes us to have a belief without providing a reason for which we believe. Since in such cases evidence is a mere cause and not a reason for which we believe, the evidentialist is committed to the claim that we do not believe for a reason in these cases although we brought the belief about for a reason. However, according to Rinard, this is implausible, and we should therefore accept that we believe for practical reasons in these cases. Call this the argument from mere causation.

Interestingly, the argument from mere causation rests on Rinard's following point about motivation:

This view [that we sometimes believe for no reason even though we brought about the belief for a reason] comes with a high cost: it is hard to square with

\footnotetext{
14 Rinard (2017, 217-218) claims that any consideration that favors a belief by indicating its practical value is a reason for this belief, thereby implying that she does not commit to the motivational constraint. However, she also defends the view that practical reasons for belief can meet the motivational constraint (cf., e.g., the references in note 11).
} 
commonsense views about motivating reasons in certain non-doxastic cases. Consider, for example, the cases [...] of breaking the window, or slowing down when you see the police car. In these cases we are happy to say that the reasons for which the agent breaks the window, or slows down, are practical. We are happy to say this even though the way in which the agent did these things was to put in motion a multistage causal process that ultimately brought about the desired result. (Rinard, 2019b, 775)

Rinard presents this argument from indirect motivation in more detail in an earlier article (cf. Rinard, 2015). The central claim is that sometimes we $\varphi$ for a reason $\mathrm{R}$

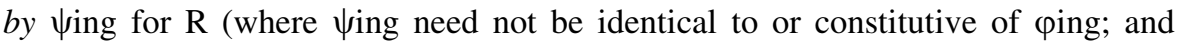
where ' $\varphi$ ' might be an action, a belief, or even a non-intentional state; while $\psi$ ing, I take it, must refer to an action). If we were to deny this claim for reasons for belief-i.e., by arguing that we do not believe for $\mathrm{R}$ when we bring about the belief for $\mathrm{R}$ - then we would sometimes believe for no reason even though we brought the belief about for a reason (assuming that Rinard's cases from mere causation by the evidence are possible). Interestingly, the argument from mere causation therefore presupposes the soundness of the argument from indirect motivation.

Rinard illustrates the argument from indirect motivation with the following case:

[S] uppose you're getting ready to go snowshoeing, and you are trying to decide which socks to wear. Last time you wore cotton socks, and your feet were too cold. You know wool is warmer than cotton, and so you'll be more comfortable if you wear wool. Surely this constitutes a genuine pragmatic reason in favor of wearing wool socks. But note that appreciating this consideration does not lead you directly to wearing them; it leads you directly only to an intention to take steps toward wearing them, such as opening your dresser drawer, finding and removing the wool socks, etc. So it fails Shah's requirement for a consideration to count as a genuine reason. But surely the fact that you'll be most comfortable if you wear wool socks does constitute a genuine reason for wearing them. (Rinard, 2015, 212-213)

Rinard points out that the fact that I have to first form the intention to wear wool socks, and then open the drawer, get them out, and put them on, before I finally wear them is not in conflict with the fact that I end up wearing the wool socks for a reason-namely, the same reason for which I formed the intention to wear them, opened the drawer, etc. Analogously, the fact that I first have to form the intention to bring a belief that $\mathrm{p}$ about and then take certain steps to bring the belief that $\mathrm{p}$ about before I finally believe that $\mathrm{p}$ is not in conflict with the fact that I believe for $a$ reason-namely, for the same reason for which I brought my believing about, which was a practical reason. Thus, Rinard concludes, there are practical reasons for belief.

I will reply to the new pragmatist's strategy by examining the limits of the argument from indirect motivation, and thereby also the limits of the argument from causation. For the latter argument presupposes the former. The discussion therefore focuses on the argument from indirect motivation. I briefly return to the argument from causation in conclusion. 
I start in Sect. 3 by presenting the evidentialist's response to the argument. Evidentialists should grant that beliefs can be indirect responses to practical reasons. But evidentialists should then argue that any practical reason that motivates belief indirectly is reducible to a reason for a basic action: it is not a genuine reason for belief.

Throughout Sect. 3, I will assume that the argument from indirect motivation draws on an analogy between reasons for belief and reasons for being in nonintentional states. This is not uncontroversial, especially given Rinard's example of 'wearing wool socks'-which we might intuitively understand as a non-basic action, rather than as a state. However, we should be careful not to be misled by grammar: even though 'wearing' is the participle form of a verb, wearing is hardly something you actively do. 'What did you do this weekend?'-'I wore my wool socks.' This reply is at best a joke, meaning that one did not really do anything special at all. ${ }^{15}$

I consider an objection to this assumption in Sect. 4. There I discuss whether the argument from indirect motivation should be read as drawing an analogy between beliefs and non-basic actions, rather than as an analogy between beliefs and nonintentional states. I argue that this is not a fruitful way of understanding the argument. First, it would make the evidentialist's reduction of practical reasons for belief to reasons to act even more plausible, for basic actions are constitutive for non-basic actions, but not constitutive for states. Secondly, beliefs can hardly be understood as non-basic actions. They are more plausibly states.

\section{Practical reasons for belief as state-reasons}

Consider how an evidentialist could set out a reply to the argument from indirect motivation. In a first step, the evidentialist could grant that we can talk about 'a practical reason to wear wool socks'. In a second step, they could then deny that this implies that there are genuine practical reasons for wearing wool socks. That is, they could argue that statements about reasons to be in states are mere elliptical references to reasons for bringing yourself into the state, or for maintaining the state. Strictly speaking, there are no practical reasons to $b e$ in a state.

Consider, for instance, the following statement: 'You should be outside-it is such nice weather today!' This sentence does not imply that you can just like that be outside by responding to the stated reason. Yet the sentence implies, in some sense, a reason to be outside. It would be absurd to say this sentence to someone who is currently incapable of going outside because they are, say, locked in for the whole day. In such a case, it could at best be understood as a mere evaluative statement, rather than as a normative one: it would merely state that it would be good for you to be outside, but not that you have a genuine reason. The absurdity in this case seems

\footnotetext{
15 Cf. Setiya's $(2013,181)$ distinction between present participles that often refer to something dynamic (shaking, buying, starting) and those that refer to something static (being red, owning, knowing). Cf. also Chrisman $(2012,598)$, who provides further examples for sentences that employ the progressive form of a verb without describing activity.
} 
to stem from the fact that we normally use such sentences as implying reasons. They are not normally just disguised evaluative claims. At the same time, it seems that the implied reasons are not genuine reasons to be in the state, but rather reasons to act: a 'reason to be outside' is a reason to ensure that you are outside by going outside or by staying there.

Thus, if the argument from indirect motivation is best understood as establishing that there are practical reasons for belief in the same sense as there are practical reasons for being in non-intentional states, then it crucially rests on the falsity of the evidentialist's reductive analysis of reasons to be in states. Let us call such a reason a

state-reason: a practical consideration that figures in the kind of reasonrelation that sometimes holds between practical considerations and nonintentional states.

Common examples of state-reasons are your reason to be outside (the weather is nice), your reason to be in London next year (there is an important conference), your reason to be a philosopher (it makes your life more meaningful), and your reason to wear a hat (it makes you more stylish). Such considerations are practical because they indicate the value of the respective state, thereby giving us, in some sense, a reason to be in that state. Intuitively, state-reasons seem to be analyzable in terms of reasons for bringing states about, or reasons to maintain them, which is why the latter reasons seem to be more fundamental. If they are indeed analyzable in this way, then the fact that there are practical state-reasons for belief will not support pragmatism. For evidentialists are fine with practical reasons for bringing beliefs about or for maintaining beliefs. ${ }^{16}$

Here is a first objection to my interpretation of the argument from indirect motivation. The new pragmatists could contend that the argument does not merely establish that there are state-reasons for belief. Rather, it establishes a stronger claim: that we can be in states for practical reasons-including states of belief-in the same sense as we can act for practical reasons. This is because one can also never just act as a direct response to a reason. Rather, when we act, it is the intention to act that is a direct response to the reason, rather than the action itself (Rinard, $2015,215)$. Therefore, if evidentialists want to exclude practical reasons for belief on the grounds 'that genuine reasons for $\phi$-ing must be capable of leading the agent directly to $\phi$-ing, with no causal intermediaries' (ibid.), they are also forced to deny genuine practical reasons for basic actions. Surely this is absurd.

But this objection implies that we can never act directly for reasons. As Joseph Raz $(2011,57)$ points out, this would be 'to misconceive the relations of intention and action, imagining that when acting intentionally one acts by forming an

\footnotetext{
${ }^{16}$ I avoid the label 'state-given reason' for two reasons. First, the distinction between state-given and object-given reasons is meant to be applicable only to intentional states, while state-reasons are also (and primarily) reasons for being in non-intentional states. Secondly, the claim that there are state-given reasons for belief is often viewed as controversial. By contrast, state-reasons for belief are uncontroversial as long as we remember that they might turn out to be nothing but reasons to bring a state about, or to maintain it.
} 
intention that causes one to act'. Even if one is not willing to accept that one can put on wool socks as an immediate response to reasons, it seems that one should accept that one can perform the basic actions involved in putting on wool socks (moving one's limbs) directly for reasons-on pain of otherwise excluding our bodily movements from the reach of our direct control.

However, let us grant to Rinard that intentions are causal intermediaries whenever we perform basic actions for reasons. ${ }^{17}$ Does that imply that basic actions cannot-like states in general-be immediate responses to practical reasons?

Not if we distinguish between causal and motivational immediacy. ${ }^{18}$ It is true that when we act for a reason, many causal processes take place in our body before we perform the action. Some of these causal processes might include an intention to act-maybe it is even true that we always form an intention to act before we act. However, none of this implies that only the intention, but not the action causally resulting from the intention, is motivationally immediate. For we do not perform an action by first forming an intention-in the same way as we do not perform an action by first firing our neurons. That is, neither our intention nor the firing of our neurons is a means that we could take in order to perform an action. Rather, as Rinard points out herself $(2015,216)$, intentions are themselves not under our direct voluntary control. ${ }^{19}$ This is why intentions cannot be motivational mediators. Therefore, as long as we keep causal and motivational immediacy apart, we can say that our basic actions are often-in contrast to states and non-basic actionsmotivationally direct responses to practical reasons.

If I am right that the argument from indirect motivation is meant to conclude that there are state-reasons for belief, then it presupposes that state-reasons are not just reducible to reasons for causing the state: the content of 'a reason to be in states' must be more than merely 'a reason to bring oneself into (or to maintain) s'. As we will see, this will give the debate on evidentialism and pragmatism an interesting dialectical shape. For it highlights how thinking about state-reasons and their relationship to reasons for action is central to the dispute: the new pragmatists have to argue that state-reasons are irreducible; while evidentialists must argue that they are reducible so as to avoid new pragmatism. ${ }^{20}$

\footnotetext{
17 Cf. Mele (1997, 242-243) for some opposition to the view that deciding always involves an intention to so decide, and for further references on this discussion.

18 The distinction is inspired by Bennett (1990, 105-106), who calls the causal immediacy 'ontological'. He argues that we cannot form a belief without first inducing causal changes in the body, but he points out that this does not prove that we cannot believe at will-i.e., believe directly without motivational mediation. Cf. also Leary $(2017,536$, n. 11) for a similar distinction and criticism of Rinard's appeal to causality instead of motivation.

19 Rinard supports the claim by appeal to Kavka's (1983) toxin puzzle.

20 As an anonymous referee pointed out to me, the idea that state-reasons are relevant to the debate on pragmatism is not particularly new. Arguably, any evidentialist who has argued that purported practical reasons for belief are actually just reasons for bringing belief about, or for trying to do so, or for intending to do so, or for desiring to believe, was concerned with state-reasons for belief (cf. notes 2 and 12 for references; cf. Berker, 2018, 482, n. 22 for a very helpful overview). On the pragmatist's side, Rinard (2017) argues that belief is subject to the same practical norms as any non-intentional state. Reisner (2009) sometimes puts his pragmatism in terms of there being practical reasons to have a belief (266-267), or practical reasons for 'ending up in a belief state' (271). (Cf. my discussion of his argument
} 
There are two worries about how state-reasons could be central to the dispute between evidentialism and pragmatism. The first is that 'wearing wool socks' is not a state but a non-basic action, and that I therefore misinterpreted the analogy of the argument from indirect motivation. I turn to this objection separately in Sect. 4 below. As we will see, it can be easily rejected.

The second worry is that state-reasons are reasons for non-intentional states, while reasons for belief are reasons for intentional states-namely, belief. But why should discussing the former reasons help us to illuminate the latter?

To address this second worry, we first need to remind ourselves that the argument from indirect motivation is an argument by analogy. It claims that sometimes, the reason-relation between a fact that supports a belief and the supported belief is the same as the reason-relation between a fact that supports your wearing wool socks and your wearing wool socks. The indirectness of the reason-relation does not, so the argument goes, preclude the fact from being a genuine reason for the response it supports. However, I have pointed out that this only holds if the state-reason for wearing wool socks-or, respectively, for belief_-is not merely a reason for putting on wool socks and for not taking them off-or, respectively, for bringing oneself into the state of belief and for maintaining it. Since the argument relies on this analogy to non-intentional states, it must be understood as pointing out that nonintentional states and intentional states belong to the common category of states, and that there can be practical reasons for anything that falls into this common category. What we therefore can conclude from the argument from indirect motivation is that there are practical reasons for belief as there are practical reasons to be in any non-intentional state: there are state-reasons for belief. However, my point is that this does not, by itself, establish that there are genuine practical reasons for belief. Rather, the argument crucially hinges on the assumption that statereasons are not just reasons to act.

It is helpful to consider some examples of claims that might express state-reasons for belief in order to get a closer grip on the idea that some reasons for belief are state-reasons. Having decisive state-reasons for a belief would amount to a 'doxastic state-ought': a practical requirement to be in a certain state of belief. ${ }^{21}$ If the evidentialist's reductive analysis of state-reasons was correct, then any expression of a doxastic state-ought would amount to a claim about what an agent should do in order to bring about or maintain a state of belief. I suspect that we sometimes do

\section{Footnote 20 continued}

from 'blocked ascent' in Sect. 6.) Furthermore, Stich $(1990,133)$ already claimed that the practical value of states of affairs that are the outcome of our cognitive processes is central to cognitive evaluation.

However, my argument here is more specific. My claim is that the new pragmatist's strategy depends on the irreducibility of reasons to be in non-intentional states-this claim has not been defended before, as far as I know. Recognizing this will present the debate in an interesting shape by clarifying the pragmatist's and evidentialist's dialectical options. Cf. esp. Sections 5 and the end of the concluding Sect. 7 on this dialectical shape.

21 Cf. Chrisman $(2008,2012)$ on doxastic state-oughts and on how they might imply reasons to act. However, note that Chrisman's project is to understand the epistemic ought as a state-ought. What I am proposing here, by contrast, is that doxastic state-oughts are often not epistemic, but rather straightforwardly practical claims about what one ought to do. 
express such oughts in our ordinary normative discourse about belief. Many of them might be disguised as simple claims about what one ought to believe. For we do not normally say 'you ought (or you have a reason) to be in the state of believing that p' or 'you ought to bring about the state of believing that p'. Here are some potential examples of such doxastic state-oughts, disguised as simple claims about what one ought to believe:

(a) 'you ought to (or should) believe in human-induced climate change'

(b) 'people ought to have no racist beliefs'

(c) 'the shipowner ought not just have believed that the ship is sea-worthy, ${ }^{22}$

(d) 'you ought to believe in God'23

In many contexts such claims might express just an epistemic obligation to fit one's belief to one's evidence. However, in other contexts they might instead express that there are decisive state-reasons for belief-i.e., practical reasons for being in the state of belief. This allows us to say that at least sometimes, the person who violates such an ought does not merely commit an epistemic mistake, but also a practical one. ${ }^{24}$ That also allows us to explain why we sometimes show distinctively moral reactions-like resentment or indignation - to someone who fails to comply with an ought to believe. For when one violates a state-ought-to-believe, one fails to comply with practical reasons (i.e., state-reasons), not just with epistemic reasons.

It is important to emphasize how this use of 'ought to believe' can be compatible with evidentialism. That there are doxastic state-oughts does nothing, by itself, to show that pragmatism is true. ${ }^{25}$ For evidentialists can argue that, insofar as we show distinctively moral reactions to those who fail to comply with these oughts, we blame them for failing to inquire, or to reflect, or for not participating in the religious life, or for directing their attention in questionable ways - rather than for

\footnotetext{
${ }^{22}$ Remember that, in Clifford's (1877) thought-experiment, the shipowner is at least partially blamed for failing to engage in impartial inquiry — which is why the heading of Clifford's first section is 'The Duty of Inquiry'.

${ }^{23}$ Pascal (1670) advises us that we should participate in the religious life if we are unable to believe in God just like that. And William James $(1896,11)$ advises us to sometimes allow our passional nature to take over when we form religious beliefs-which suggests strategies consisting in the performance of mental actions. Interestingly, both Clifford and James were to a great extent concerned with the question of how to manage our doxastic lives-which explains even from an evidentialist's point of view why the background for their ethics of belief was practical (cf. Lindner, 2020; Mitova, 2010 for arguments why Clifford was a 'closet pragmatist').

24 I say 'sometimes' because, as an anonymous referee pointed out to me, someone other than the person who 'ought to be' in that state might be committing the practical mistake. For instance, if children ought to believe that the earth is round, then parents and teachers might be responsible for ensuring that children have this belief, and they are morally to blame if they fail to make it true that children comply with the state-ought. Chrisman $(2008,2012)$ in particular highlights this interpersonal dimension of state-oughts. See Chrisman (2020) on his social approach to epistemology.

25 I misleadingly claimed in the concluding section of Schmidt (2017) that the existence of doxastic state-oughts supports a version of pragmatism. It only would support pragmatism if these state-oughts were irreducible.
} 
just being in the state of believing. ${ }^{26}$ That is, evidentialists can argue that stateoughts and state-reasons are ultimately just reducible to reasons to act. This argumentative strategy, in combination with the observation that we sometimes use 'ought to believe' as implying state-reasons, provides evidentialists with a basis for an attractive error-theory about purported practical reasons for belief that we sometimes express in ordinary discourse. ${ }^{27}$

This section has argued that the argument from indirect motivation presupposes that state-reasons are irreducible. I will consider their (ir)reducibility more closely in Sect. 6. However, let us first consider an objection to the conclusion of this section, mentioned briefly above: maybe we misunderstood the argument from indirect motivation by reading it as appealing to state-reasons; for maybe 'wearing wool socks' was meant by Rinard not as an example of a state, but rather as an example of a non-basic action.

\section{Practical reasons for belief as reasons for non-basic actions?}

Rinard gives more examples than just 'wearing wool socks' in order to support her claim that indirect motivation is sufficient for there being practical reasons for belief. These examples suggest that her point is not that practical reasons for belief are state-reasons. She could therefore, in principle, grant that state-reasons are reducible to reasons to act, but argue that the argument from indirect motivation is meant to establish a different analogy_namely, between reasons for belief and reasons for non-basic actions. Here are Rinard's further examples:

For example, that air pollution is worse in the city is a reason to live in the country; that it'll be easier for you to pay attention during a talk if you sit in the front row than the back is a reason to sit in the front; that doing so would be relaxing is a reason to spend some time in Costa Rica; etc. But none of these considerations plays the particular role in the regulation of one's $\phi$-ing identified by the Evidentialists as necessary for it to count as a genuine reason. (Rinard, 2015, 213)

\footnotetext{
${ }^{26}$ Note, importantly, that many evidentialists are fine with the claim that we show distinctively epistemic reactions towards people just because these people are in a state of belief that is insufficiently supported by their evidence (even if the person lacked control over whether they are in this state). Such reactions might include epistemic distrust and other distinctively epistemic reactive attitudes. Whether the appropriateness of epistemic blame presupposes control is a different question from whether reactions such as indignation and resentment presuppose control. Failing to distinguish between different kinds of reactive attitudes that presuppose different kinds of capacities is the main reason why we get puzzled about how we can be responsible not only for our actions, but also for our attitudes (Schmidt, 2020). See Boult (2020, 2021a), Brown (2018), and Kauppinen (2018) on the nature of distinctive epistemic blame or criticism. See Boult (2021b) for a recent overview of the literature on epistemic blame. See Schmidt (2021) on how appealing to epistemic blame can help us make sense of a distinctively epistemic kind of normativity.

27 Another instance of such a use of 'ought to believe' can be found in Price (1954), who argues that doxastic oughts are made true by our ability to direct our attention and thereby cause ourselves to believe.
} 
Again, Rinard's claim is that we cannot just live in the country, sit in the front row, or spend time in Costa Rica as direct responses to reasons-in the way we can perform basic actions as direct responses to reasons, or form beliefs as direct responses to the evidence; nevertheless, the reasons for which we perform those non-basic actions are reasons for those actions.

These complex actions are long-term activities which aim at bringing about or keeping up a certain state of affairs - the states that you live in the country, sit in the front row, or spend time in Costa Rica. Evidentialists can react to these cases in the same way as they react to state-reasons: by arguing that reasons for long-term activities are analyzable in terms of the reasons we have for performing basic actions. Engaging in a long-term activity is not a motivationally immediate response in the way performing basic actions are motivationally immediate responses to practical reasons. Therefore, if there are reasons for belief in the same sense in which there are reasons for long-term activities or non-basic actions, they won't pose a problem for evidentialism if they are in fact just fully analyzable in terms of reasons for basic actions. This reductive analysis is especially plausible insofar as basic actions are constitutive of non-basic actions, while basic actions are not constitutive of the states that are caused by them.

There is another serious disadvantage for reading the argument from indirect control as appealing to activities rather than to states. While beliefs are plausibly conceived of as states, they are not so plausibly conceived of as activities-except if we endorse a strong version of doxastic voluntarism. I do not deny that believing is essentially accompanied by long-term activities, like by what Chrisman (2018) calls 'maintaining a coherent system of beliefs' - an activity he takes to be crucial for understanding epistemic normativity. However, the view that beliefs are themselves long-term activities done for practical reasons seems to be confused. For one, we do not perform long-term activities for practical reasons while asleep, but we do not stop believing what we believe while asleep (cf. Boyle, 2011, 6). Furthermore, we can partially explain why we perform long-term activities by reference to beliefstates: my aunt lives in the countryside because she believes that it is quiet there, and because she appreciates a quiet life. In order for beliefs to serve such an explanatory function, they cannot be long-term activities themselves, but must be conceived of as stable dispositions (cf. Chrisman, 2018, 514). Finally, I take it that discussions about reasons for belief and norms of epistemic rationality are supposed to concern reasons and norms for states of belief. If we instead ask for the norms that govern certain activities that we call 'believing', we just change the topic: we talk about the normativity of a different kind of entity than the entity those debates are concerned with. This new entity might be closely related to states of belief, but it is not what most philosophers wish to talk about when discussing doxastic normativity. ${ }^{28}$

\footnotetext{
28 Boyle (2011) and Hieronymi (2009; ms) conceive of beliefs as 'active states'. Importantly, however, both agree that this category of active states (which I term 'intentional states') is different from intentional actions that we perform for practical reasons. Hieronymi explicitly distinguishes between 'managerial control' (the kind of control we exercise when we perform actions for practical reasons) and 'evaluative control' (the kind of control we exercise when we, e.g., believe for epistemic reasons). Boyle
} 
I will therefore not discuss further the option of whether practical reasons for belief could be understood by modelling them on practical reasons for long-term activities, or for other non-basic actions. It seems much more promising for the pragmatist to explore the relationship between state-reasons and reasons for action in order to develop a substantial notion of practical reasons for belief. For belief is plausibly conceived of as a state, but not so plausibly as a non-basic action. Furthermore, reasons for non-basic actions are more plausibly reducible to reasons for basic actions than reasons for states insofar as basic actions are constitutive of non-basic actions but not constitutive of states.

\section{The pragmatist's options: irreducible state-reasons or doxastic voluntarism}

Rinard $(2015,213)$ agrees that in the case of reasons for states (and long-term activities), 'the causal connection between the pragmatic consideration for $\varphi$-ing, and the agent's actually $\varphi$-ing, is complex and indirect'. This already highlights an important distinction between being in a state for a reason by performing an action for this reason, on the one hand, and performing a basic action directly for a reason or believing directly on the basis of evidence, on the other. This distinction gives rise to the two possible strategies (i) and (ii) which I mentioned in the introductory section of this paper: Since any motivation of a response by a reason is either indirect or direct (either there is a motivational mediator or there isn't), pragmatists must employ at least one of these strategies if they wish to argue that there are practical reasons for belief that satisfy the motivational constraint. This section elaborates on these two options in more detail.

Consider:

The new pragmatist's strategy (corresponding to option (i)): Practical reasons can motivate belief via motivationally intermediate actions that then result in belief, so that the relation between the reason and the response to the reason is indirect (as in the case of reasons for states, or reasons for long-term activities and other non-basic actions).

The traditional pragmatist's strategy (corresponding to option (ii)): Practical reasons can motivate belief without motivationally intermediate actions, so that the relation between reason and response is that of being directly based on the reason (as in the case of performing basic actions for reasons, or in the case of believing directly on the basis of evidence).

Consider first the new pragmatist's strategy in light of my overall argument. This strategy appears to put pragmatists on the safe side insofar as it is rather uncontroversial that we can at least exercise indirect control over some of our beliefs (cf. note 8 for examples). By contrast, it is much more controversial whether

Footnote 28 continued

and Hieronymi agree that belief is an activity, but one that importantly differs from intentional actionthis is precisely why they think that we need a separate account for this sui generis activity. 
we can control beliefs as directly as we can control basic actions. The new pragmatist therefore rightly emphasizes that beliefs can be motivationally indirect responses to practical reasons. Throughout the previous sections, I have contended that their argument from indirect motivation is best understood as drawing an analogy between reasons for belief and reasons for non-intentional states (wearing wool socks, being a philosopher, being able to play the piano). The new pragmatists therefore establish that there can be practical reasons for belief as there can be practical reasons for non-intentional states.

However, maybe surprisingly, evidentialists can grant this conclusion. They can agree that we sometimes say such things as 'you ought to wear wool socks', 'you ought to be a philosopher', 'you ought to be able to play the piano', thereby making not merely evaluative statements, but implying practical reasons for a person to be in that state. Analogously, they can agree that 'you ought to believe in humaninduced climate change' or 'you ought to have no racist beliefs' sometimes imply practical reasons for being in that doxastic state (cf. end of Sect. 3). However, the evidentialist will then argue that by saying such things, we merely refer elliptically to reasons for actions. In order to wear wool socks, you have to put them on; in order to be a philosopher, you have to take steps to become one; and in order to be able to play the piano, you have to practice. Analogously, in order to have no irresponsible or disrespectful beliefs, you have to fulfill your duties of inquiry, monitor your implicit biases, or ensure that your mind is sufficiently rational by, say, taking care of yourself. That is, evidentialists will argue that there are practical state-reasons only insofar as the actions that are likely to bring the state about are supported by reasons. Evidentialists have no problem allowing for 'practical reasons for belief' in this sense - at least as long as we grant that these are indeed reducible to reasons for action (an issue I discuss in Sect. 6). This is why pragmatists who appeal to indirect motivation have to argue that state-reasons are not just reducible to reasons to actwhich is dialectical option (i) for pragmatists (cf. Sect. 1).

Consider the next option (ii) for pragmatists - the traditional pragmatist's strategy. This strategy is to argue that practical reasons for belief meet the motivational constraint because practical reasons can motivate belief not only indirectly, but also directly. Traditional pragmatism holds that we can sometimes believe directly for practical reasons in the way we can just perform basic actions directly for practical reasons, or in the way we can believe directly on the basis of evidence (cf. McCormick, 2015, 2020; Rinard, 2019a, 1944-1945, 2019b, 778-780). The main challenge for this view is to show that a belief that directly results from considering a practical reason is not merely caused, but actually based on the practical reason. ${ }^{29}$ Yet it is important to see that meeting this challenge does not commit traditional pragmatists to a stronger claim: that we can sometimes explicitly decide to believe for practical reasons (as defended by, e.g., Ginet, 2001).

\footnotetext{
${ }^{29}$ Cf. Carter and Bondy (2020) on the recent debate on the epistemic basing-relation. As I noted in the introductory section, all kinds of factors cause and influence our beliefs without being reasons for which we believe. Traditional pragmatists must show that practical reasons sometimes do not merely cause our beliefs directly but rather provide good direct bases for belief (which, of course, might just consist in causing them in the right way). Cf. note 30 on believing at will as believing directly for practical reasons.
} 
Instead, it is open for them to argue that there are less explicit ways of believing directly for practical reasons than deciding to believe. For instance, McCormick (2015) has argued that the way we control beliefs is sometimes analogous to the way we control many actions that are less than fully voluntary, intentional, or conscious. One of her examples is taking each individual step for a reason while going for a walk (ibid., 82). She supports this analogy between control over actions and control over beliefs by arguing that we have guidance control over both-i.e., she argues that beliefs are often responsive to practical reasons in the same way as actions are often responsive to practical reasons.

Here I am not concerned with whether such strategies for defending the idea that we can believe directly for practical reasons are successful. It is thus open for traditional pragmatists to argue that 'believing directly for practical reasons' allows for a reading that is not just restricted to explicit decisions to believe, and that this more permissive reading is already sufficient for practical reasons for belief to pass the motivational constraint. ${ }^{30}$

My main point in this paper is rather that the argument from indirect motivation does not, by itself, establish pragmatism. All the argument from indirect motivation shows is that we can 'believe for practical reasons' in the sense that we can indirectly respond to state-reasons for belief. But this might well be compatible with evidentialism. For state-reasons for belief could be reducible to reasons to act. By reducing state-reasons for belief, the evidentialist can deny irreducible practical reasons for belief, which are presupposed by the new pragmatist's argument from indirect motivation. Their argument therefore does not, by itself, establish that evidentialism is false. The new pragmatists owe us an argument why state-reasons are irreducible.

I will summarize the dialectical landscape sketched here in the concluding section. First, however, I will present an argument that state-reasons are reducible. I will argue that irreducible state-reasons are hard to square with the motivational constraint on reasons. The new pragmatist's strategy therefore does not amount to a satisfying reply to the new evidentialists (cf. note 2).

\section{The logic of state-reasons}

The argument from indirect motivation establishes that there are practical statereasons for belief. I therefore agree with Rinard $(2019 \mathrm{~b}, 775)$ that it would be absurd to 'say that, in general, we do not have motivating reasons for anything we do indirectly'. There is a sense in which we can have a motivating reason for being in a

\footnotetext{
30 There is no fixed use of 'believing at will' in ordinary language, and philosophers like Bennett (1990) and Hieronymi (2008) define it as believing directly for practical reasons, and they contrast it with (a) believing indirectly for practical reasons (causing belief) and (b) with a belief's merely being caused by practical considerations. In case (a), the belief would not be directly based on the reason; in case (b), it would not be based on the reason at all. I argue in Schmidt (2016) that all purported cases of believing directly for practical reasons fall either into (a) or (b), so that there are no cases in which we believe directly on the basis of a practical reason.
} 
non-intentional state. Therefore, there can be practical reasons for being in states of belief in precisely this same sense. However, as long as the pragmatist does not present us with an argument why state-reasons aren't just reducible to reasons to act, they do not support the view that there are genuine practical reasons for belief.

Since the new pragmatists want to show that practical reasons can meet the motivational constraint, this section will be concerned with the following question:

Are state-reasons irreducible if the motivational constraint is true?

In a first step, I will argue that the strictest version of the motivational constraint implies that whenever you have a state-reason, you also have a reason to act (i.e., a reason to bring the state about, or to maintain it) (Sect. 6.1). In a second step, I will argue that even the weakest version of the motivational constraint still implies that whenever you have a state-reason, you also have a reason to respond to this statereason (i.e., a reason to act, to try, to intend, or to desire) (Sect. 6.2). In a final step, I argue that the new pragmatists therefore face the challenge of giving us an account of the theoretical purpose for assuming irreducible state-reasons as normative entities over and above the reasons for the responses that these state-reasons imply (Sect. 6.3). Without such an account, we have no reason to assume that there are irreducible state-reasons.

One last preliminary: my discussion will focus on reasons for non-intentional states. My argument throughout Sects. 2-5 has revealed that they are central for discussions about practical reasons for belief. However, just to be clear, I will briefly summarize why reasons for non-intentional states are relevant. My main point up to now was that the new pragmatist's strategy relies on an analogy between practical reasons to be in non-intentional states and practical reasons for being in belief states. It establishes that there can be practical reasons for belief as there can be practical reasons to be in non-intentional states. These are what I have dubbed 'state-reasons' for belief. The new pragmatist treats states of belief as if they were non-intentional states one can be in (cf. esp. Rinard, 2017). This is why any argument concerning reasons for non-intentional states will be applicable to statereasons for belief: state-reasons for belief just are the kinds of practical reasons for belief that we get when we treat belief like just another non-intentional state.

\subsection{State-reasons and reasons to act}

Consider the strictest version of the motivational constraint:

Motivational Constraint (strict version) (MC). A consideration $\mathrm{R}$ is a reason for you to $\varphi$ only if you can $\varphi$ for $\mathrm{R}$.

If we apply MC to state-reasons, it says that $\mathrm{R}$ is a reason for you to be in a state $\mathrm{s}$ only if you can be in s for R. But what does it mean to be in a state for a reason? It means that you brought the state about for that reason, or that you are maintaining the state for that reason. Therefore, MC implies: 
state-reasons imply reasons to act (SRRA). $\mathrm{R}$ is a reason for you to be in $\mathrm{s}$ only if $\mathrm{R}$ is a reason for you to bring $\mathrm{s}$ about, or to maintain $\mathrm{s} .{ }^{31}$

The only step that requires clarification is why 'being in a state for a reason' means that you brought it about for that reason, or that you maintain it for that reason. To see the plausibility of this step, we have to remember that we are concerned here with non-intentional states. Consider, for instance, your reason to be at the top of a mountain (say, you would be rewarded with an enjoyable view). There are of course countless ways in which you might end up complying with that reason. You could climb up to the top, for instance, or stay at the top if you are already there because you want to enjoy the view a little longer. In these cases, you can be said to be at the top for a reason: you climbed up for the enjoyable view, or you stayed there for the enjoyable view. In other cases, you might comply with your reason to be at the top because you are brought to the top by external forces: someone else might drag you up against your will, or a strong gust of wind might carry you up. In these cases, you still end up complying with your reason-after all, you end up being in the state that your reason supports. However, you won't be at the top of the mountain for a (normative) reason. Rather, you merely comply. We can then merely explain why you are up there by citing the causal factors that brought you there. But these factors are not reasons for which you are at the top-i.e., they are not your motivating reasons. Therefore, you can only be said to be at the top of the mountain for a reason if you are, in a broad sense, exercising your own agency by climbing up for that reason, or by staying there for that reason.

This seems to hold for all non-intentional states. Whenever you are brought into or kept in a state without exercising your own agency, you are not in that state for a reason. But the only ways of exercising your agency that would get you into a nonintentional state are bringing yourself into the state for a reason and maintaining the state for a reason. ${ }^{32}$ Therefore, whenever you are in a non-intentional state for a reason-and thus whenever you are in a state of belief for a state-reason-you have either brought yourself into that state for that reason or you maintained that state for that reason. I conclude that MC implies SRRA. ${ }^{33}$

\footnotetext{
31 To be precise, MC and my analysis of 'being in a state for a reason' imply that $\mathrm{R}$ is a state-reason for you to be in $\mathrm{s}$ only if you can bring about $\mathrm{s}$ for $\mathrm{R}$ or maintain $\mathrm{s}$ for $\mathrm{R}$. But if you can $\varphi$ for a reason $\mathrm{R}$, then $\mathrm{R}$ is a reason for you to $\varphi$. From this we can deduce SRRA. Thanks to Franziska Poprawe for urging me to make this explicit.

32 Interestingly, this does not hold for intentional states. You can believe on the basis of evidence without bringing the belief about for a reason or maintaining it for a reason. And if the traditional pragmatists were right, you could believe directly for practical reasons without bringing the belief about for a reason or maintaining it for a reason. Note, however, that this is so only if we read 'bringing about' and 'maintaining' as referring to actions-i.e., as something we can do directly for practical reasons. There is another, passive, sense in which you will always 'bring about' a belief whenever you come to believe something and 'maintain' a belief whenever it persists from one moment to the next. But these are not the active senses of 'bringing about' and 'maintaining' that I am employing here.

33 While developing this argument, I noticed that there is another interesting way of defending SRRA that does not rely on MC. Suppose you have a reason to be at the top of the mountain. In order to be at the top, you will have to climb up or stay there. Thus, climbing up or staying there are (taken together) a necessary means for being at the top for a reason. More generally, bringing a state about or maintaining a state are (taken together) a necessary means for being in a state for a reason. Therefore, if we assume that
} 
Before proceeding to the final step of my argument-namely, to show that the new pragmatists face a serious challenge if they accept SRRA but maintain that state-reasons are irreducible-we need to consider whether weaker versions of the motivational constraint than MC also imply SRRA. For the new pragmatists might argue that $\mathrm{MC}$ is too strong, and instead accept a weaker version of the constraint in order to avoid SRRA. I will argue that weaker versions of MC either do imply SRRA or at least imply a claim similar to SRRA that will give rise to a challenge very similar to the one to which SRRA gives rise.

\subsection{State-reasons and reasons to respond}

To see how MC might be too strong, consider first how it is incompatible with Reisner's $(2009,271)$ 'argument from blocked ascent'. Suppose that you would get a huge reward for being at the top of the mountain, but that you won't get the reward if you take any means to get up there (e.g., climbing). Suppose furthermore that you are not already at the top of the mountain. Reisner thinks the reward still provides you with a reason to be at the top even though you have no reason to bring yourself to be at the top. This would be a counterexample to SRRA. However, MC rules out that you have a reason for being in the state when ascent is blocked in this way: since you cannot even comply with your state-reason in such cases by exercising your own agency, you can also not be at the top of the mountain for this reason. If we accept MC, all we can say is that it would be good for you to be at the top of the mountain, but not that you have a genuine reason to be there. However, Reisner could then just reply that MC is too strong and must be formulated less strictly.

Weaker versions of the motivational constraint might allow Reisner's argument to go through. SRRA would then turn out to be false if we assume such weaker versions. What is the weakest version of the motivational constraint? One central feature of the motivational constraint is, as we just saw, that it allows us to distinguish the merely evaluative (what is merely good) from the normative (what is good and provides us with a normative reason) in terms of an agent's abilities. Since making this distinction is one of the main motivations for endorsing a version of the motivational constraint (cf. Way \& Whiting, 2016, 215), I will assume that any claim that could plausibly count as a version of the motivational constraint must allow us to draw such a distinction between the evaluative and the normative. The following claim fulfills this condition:

Motivational Constraint (weak version) $\left(\mathrm{MC}_{\mathrm{W}}\right)$. A consideration $\mathrm{R}$ is a reason for you to $\varphi$ only if $\mathrm{R}$ can motivate at least one of your responses (i.e., you can $\varphi$ for $\mathrm{R}$, or try to $\varphi$ for $\mathrm{R}$, or intend to $\varphi$ for $\mathrm{R}$, or desire to $\varphi$ for $\mathrm{R}$, etc.).

Footnote 33 continued

reasons for aims transmit to necessary means for that aim (as defended extensively by Kiesewetter, 2015 , 2018), any state-reason will imply a reason to bring the state about, or to maintain it. Even though I do not need to rely on a principle of necessary means transmission if I assume MC, this line of argument still seems worth mentioning, for it provides a basis for defending SRRA without assuming MC. 
$\mathrm{MC}_{\mathrm{W}}$ implies that if there is a valuable state that cannot motivate any of your responses, then this state does not provide you with a reason. Such states might include states that you are unable to know about, or states you are psychologically incapable of forming any attitude towards. This weak version therefore still captures the spirit of the motivational constraint by drawing a line between the merely evaluative and the normative. Furthermore, it is hard to see how we can formulate an even weaker version of the motivational constraint that would still draw such a line: if we allow for values that provide us with genuine reasons even though they cannot motivate any of our responses, then we will blur the line between the evaluative and the normative that the motivational constraint is meant to draw. Therefore, $\mathrm{MC}_{\mathrm{W}}$ is the weakest version of the motivational constraint. Any claim that could count as a version of the motivational constraint will at least imply that your reasons are such that they can motivate one of your responses. ${ }^{34}$

Now return to Reisner's cases of blocked ascent. If we reject MC and merely accept the weak version $\mathrm{MC}_{\mathrm{W}}$, then the reward that you get for being at the top of the mountain might still provide you with a reason to be at the top, even if you have no reason to climb up (remember that you won't get the reward if you take any means to get to the top). This is because the reward might still motivate one of your responses: you could desire to be at the top of the mountain for the reason that you would get a reward, or (in some possible worlds) hope that Scotty will beam you up. For all that $\mathrm{MC}_{\mathrm{W}}$ says, this might be sufficient for the reward to provide you with a genuine reason to be at the top-i.e., a genuine state-reason. Therefore, it seems that state-reasons do not imply reasons to act if one endorses $\mathrm{MC}_{\mathrm{W}}$ rather than $\mathrm{MC}$. It seems that the weakest version of the motivational constraint does not imply SRRA.

In reply, I grant, for the sake of argument, that you might have a state-reason to be at the top of the mountain even in cases of blocked ascent. However, even if one can avoid SRRA in this way, state-reasons will still have the following implication if we accept $\mathrm{MC}_{\mathrm{W}}$ :

State-reasons imply reasons to respond (SRRR). $\mathrm{R}$ is a state-reason for you to be in $\mathrm{s}$ only if $\mathrm{R}$ is a reason for you [to bring yourself into $\mathrm{s}$, or to maintain yourself being in s, or to try to bring yourself into s, or to try to maintain yourself being in s, or to intend to bring yourself into s, or to intend to maintain yourself being in s, or to desire to be in s, or to hope to be in s, or ...].

While SRRR won't allow us to say that state-reasons are reducible to reasons to act, it still leaves open the possibility that state-reasons are reducible to reasons for the

\footnotetext{
34 One might wish to formulate an even weaker version by appealing to counterfactuals: one has a reason $\mathrm{R}$ to $\varphi$ only if one can $\varphi$ (or try, or intend, or desire to $\varphi$ ) for $\mathrm{R}$ in at least one close counterfactual scenario. However, even if that was a plausible weakest version of the constraint, it won't help the new pragmatist. For in cases of blocked ascent, one will then have a reason to be at the top of the mountain and a reason to climb up. After all, in at least one close counterfactual scenario, your ascent won't be blocked (you would get the reward even if you climb). Assuming such a version of the constraint would thus not allow the construction of a counterexample to SRRA: both reasons to be in states as well as reasons to bring states about (or maintain them) would be equally easy to come by. Thanks to Arturs Logins for drawing my attention to this possible weaker formulation.
} 
various responses that a state-reason implies (reasons to act, try, intend, desire, hope, etc.). SRRR will therefore still give rise to a very similar challenge for the new pragmatists as SRRA does. I now turn to this challenge. ${ }^{35}$

\subsection{The challenge for new pragmatism}

I have argued that MC implies SRRA, and that any weaker version of the constraint will at least imply SRRR. To see the challenge that SRRA/SRRR gives rise to for the new pragmatists, we first have to remind ourselves that their strategy consists in showing that practical reasons for belief - which they understand as state-reasonscan meet MC. If they consequently accept SRRA/SRRR, they must argue that statereasons are still not just reducible to the reasons for the responses that are implied by state-reasons. Rather, they would have to claim that state-reasons are normative entities over and above the reasons for the responses that they imply.

However, this claim faces a serious challenge. As Derek Parfit $(2011,432)$ pointed out, 'I might truly claim, for example, that I have a reason to be in Paris next April. But [...] such reasons would have no importance. It would be enough to claim that I have reasons to want to be in Paris next April, and to go there, if I can'. He also states that 'it is not worth claiming' that one has a reason to be in a state (cf. ibid., 51). The point is, I take it, that it is not obvious at all why we should say that we have a state-reason additionally to the reasons for the responses this state-reason implies. What is the theoretical purpose of assuming such normative entities over and above the reasons for the implied responses? One such purpose is to defend new pragmatism. Obviously, however, the new pragmatists have to find an independent purpose for irreducible state-reasons.

To illustrate what I mean by such a 'theoretical purpose', consider the following possible attempt by the new pragmatist to meet this challenge. They could appeal to some explanatory relation between the state-reason and the reasons implied by it that precludes that the state-reason is just analyzable in terms of the reasons it implies: whenever a subject has a reason to bring a state about (or to maintain it, or to try to do so, etc.), this is so because they have a reason to be in the state. ${ }^{36}$ However, the main challenge for this view is to tell us why this amounts to anything more than to just saying that whenever one has a reason to bring a state about (or to maintain it, etc.), this is so because the state is valuable. It does not seem that the normative can explain

\footnotetext{
35 Berker (2018, 461-467) argues that in many cases reasons to desire (and reasons to try, and to intend) admit of a combinatorial behavior that is different from genuine practical reasons. He concludes from this that practical reasons for belief cannot be analyzed as reasons to desire (or as reasons to try, or to intend). If Berker was right, then we could also conclude that a reason to desire to be in a state won't imply that you have a practical reason to be in a state. The new pragmatists would then owe us an additional argument why we have a practical reason to be at the top of the mountain in cases of blocked ascent. The mere fact that you have a reason to desire to be at the top would not establish that you have a genuine practical reason to be there. Rather, it would seem again that you only have a practical reason to be at the top if you also have a practical reason to bring yourself there, or to maintain your state. I sympathize with Berker's argument, but for the purposes of my discussion here I need not rely on it.

36 I owe the idea that state-reasons might be explanatorily prior to reasons for action to Franziska Poprawe. Cf. also Reisner (2009, 269-270) for a very similar point.
} 
my reason to bring myself to be in the state (or to maintain it) better than the evaluative. And remember that, as I have pointed out above, as long as one wishes to retain some version of the motivational constraint, one commits to a distinction between the normative and the evaluative: the new pragmatists cannot, while pursuing their argument that state-reasons for belief satisfy the motivational constraint, just say that every good state provides one with a state-reason to be in that state. For blurring the distinction between the evaluative and the normative in this way would amount to giving up on the motivational constraint even in its weakest form.

This is, of course, not the end of the matter. I hope that my discussion gives us an idea of the kind of questions and arguments that are relevant for deciding whether state-reasons are reducible to reasons to act-which is, as I have argued in the previous sections, the central question for deciding the prospects of the new pragmatist's strategy. I have argued in this section that if pragmatists wish to preserve a version of the motivational constraint on reasons (as our new pragmatists do), they should accept either SRRA or at least SRRR. Furthermore, I have posed a challenge for any pragmatist who accepts SRRA/SRRR and at the same time wants to maintain the irreducibility of state-reasons: they have to give an account of the theoretical purpose for assuming the existence of state-reasons over and above the reasons for the responses that state-reasons imply. Finally, I have just objected to one such intuitively plausible account.

\section{Conclusion}

The overall aim of this paper was to evaluate the argument from indirect motivation, the conclusion of which is also presupposed by the argument from mere causation (cf. Sect. 2), and to thereby reshape the dialectical options for pragmatists who accept the motivational constraint. I have contended (cf. Sects. 3 and 4) that the argument from indirect motivation only establishes that there are practical reasons for belief that meet the motivational constraint if we assume that state-reasons are irreducible. That is, the new pragmatist is committed to the view that state-reasons for belief are not just reasons to bring the belief about, or to maintain it. However, we also saw (cf. Sect. 6) that the irreducibility of state-reasons is hard to maintain if one accepts the motivational constraint on reasons. The new pragmatist's argument from indirect motivation therefore seems to be incompatible with the very constraint it attempts to meet. For on any plausible version of the motivational constraint, state-reasons imply reasons to act (or to try, intend, desire). The new pragmatists owe us an explanation why we should assume that there are irreducible normative entities over and above the reasons for responses that state-reasons imply, given the motivational constraint.

The argument from mere causation (cf. Sect. 2) faces the same problem as the argument from indirect motivation. Assume once more that there are cases in which we brought about a belief for a reason and where our evidence merely caused our belief, rather than providing us with a reason for this belief. We can now acknowledge that in such cases, if these cases are indeed conceivable, there is a state-reason for which we believe. We can thus avoid the problematic conclusion that we do not believe for a reason in any sense in this case. However, as long as we have no 
argument why this state-reason is a normative entity over and above the reason for the implied responses, we have no reason to assume that there are such entities.

As I pointed out in Sect. 5, new pragmatism is not the only way for pragmatists to go. Instead of arguing for the irreducibility of state-reasons, they could instead stick to traditional pragmatism and argue that we can believe directly for practical reasons, i.e., at will (cf. note 30). That is, they could argue that practical reasons can directly motivate belief in the way they can directly motivate action. In order to do so, they must show that beliefs can be directly based on practical reasons without motivationally mediating actions (i.e., without 'bringing abouts' or 'maintainings'). This would establish that practical reasons for belief are not just reasons analogous to reasons for being in non-intentional states, but rather that they are reasons analogous to reasons that directly motivate action. Whether beliefs can be direct responses to practical reasons is controversial. But since the prospects for endorsing the motivational constraint and at the same time maintaining the irreducibility of state-reasons are dim, my overall argument suggests that defending traditional pragmatism is a more promising route than new pragmatism.

My discussion provides us with an Überblick of how one can defend a pragmatist account of reasons for belief. Rather than having scattered arguments for and against pragmatism here and there, we can now see that each argument in favor of a version of pragmatism that respects the motivational constraint needs to establish either of two claims:

(i) State-reasons for belief are not reducible to reasons to act (or to try, intend, desire, ...).

(ii) We can sometimes believe directly for practical reasons.

These are the only options for such pragmatists because in order to meet the motivational constraint, pragmatists have to appeal either to indirect motivation or to direct motivation. As I have argued, appeals to indirect motivation presuppose (i). Therefore, (i) and (ii) are the only options for defending a pragmatist account of reasons for belief that respects the motivational constraint. Pragmatists who defend only (ii) but not (i) can be called 'traditional pragmatists', while pragmatists who defend (i) but not (ii) might be labelled 'new pragmatists'. Of course, pragmatists could defend both claims. Evidentialists have to deny both (i) and (ii). I have argued against (i) by showing that it is hard to square with the motivational constraint on reasons: if we accept the motivational constraint, then state-reasons imply reasons to act (or to try, intend, desire); it is then hard to see why state-reasons should be anything over and above the reasons for those actions (or tryings, intendings, desirings).

Acknowledgements I am grateful to Arturs Logins and Franziska Poprawe for their meticulous comments on earlier drafts of this paper, as well as to two anonymous referees for their very helpful comments. Furthermore, I thank Anne Meylan and Veli Mitova for their ongoing support and encouragement. This paper benefited much from the discussion at a workshop on "Rationality, What's Good, What's Bad", organized by the Zurich Epistemology Group on Rationality (ZEGRa) in December 2019. Thanks to Kathleen McCully for her very helpful proof reading. 
Funding Open Access funding provided by Universität Zürich.

Open Access This article is licensed under a Creative Commons Attribution 4.0 International License, which permits use, sharing, adaptation, distribution and reproduction in any medium or format, as long as you give appropriate credit to the original author(s) and the source, provide a link to the Creative Commons licence, and indicate if changes were made. The images or other third party material in this article are included in the article's Creative Commons licence, unless indicated otherwise in a credit line to the material. If material is not included in the article's Creative Commons licence and your intended use is not permitted by statutory regulation or exceeds the permitted use, you will need to obtain permission directly from the copyright holder. To view a copy of this licence, visit http:// creativecommons.org/licenses/by/4.0/.

\section{References}

Adler, J. (2002). Belief's own ethics. MIT Press.

Alston, W. P. (1988). The deontological conception of epistemic justification. Philosophical Perspectives, 2, 257-299.

Bennett, J. (1990). Why is belief involuntary? Analysis, 50, 87-107.

Berker, S. (2018). A combinatorial argument against practical reasons for belief. Analytic Philosophy, 59, $527-470$.

Boult, C. (2020). There is a distinctively epistemic kind of blame. Philosophy and Phenomenological Research. https://doi.org/10.1111/phpr.12726

Boult, C. (2021a). The significance of epistemic blame. Erkenntnis. https://doi.org/10.1007/s10670-02100382-0

Boult, C. (2021b). Epistemic blame. Philosophy Compass. https://doi.org/10.1111/phc3.12762

Boyle, M. (2011). 'Making up your mind' and the activity of reason. Philosopher's Imprint, 11, 1-24.

Brown, J. (2018). What is epistemic blame? Noûs. https://doi.org/10.1111/nous.12270

Carter, J. A., \& Bondy, P. (2020). Well-founded belief. New essays on the epistemic basing relation. Routledge.

Chrisman, M. (2008). Ought to believe. Journal of Philosophy, 105, 346-370.

Chrisman, M. (2012). The normative evaluation of belief and the aspectual classification of belief and knowledge attributions. Journal of Philosophy, 109, 588-612.

Chrisman, M. (2018). Epistemic normativity and cognitive agency. Nous, 52, 508-529.

Chrisman, M. (2020). Believing as we ought and the democratic route to knowledge. In S. Schmidt \& G. Ernst (Eds.), The ethics of belief and beyond (pp. 47-70). Routledge.

Clifford, W. K. (1877). The ethics of belief. In The ethics of belief: And other essays. Prometheus Books, 1999, 70-96.

Crawford, L. (2020). Relationships and reasons to believe. In S. Schmidt \& G. Ernst (Eds.), The ethics of belief and beyond (pp. 87-108). Routledge.

Feldman, R. (2000). The ethics of belief. Philosophy and Phenomenological Research, 60, 667-695.

Flowerree, A. (2020). Evidentialism in action. Philosophical Studies, 177, 3409-3426.

Ginet, C. (2001). Deciding to believe. In M. Steup (Ed.), Knowledge, truth, and duty (pp. 63-76). Oxford University Press.

Harman, G. (1999). Reasoning, meaning, and mind. Oxford University Press.

Hazlett, A. (2013). A luxury of the understanding. Oxford University Press.

Hieronymi, P. (2005). The wrong kind of reason. Journal of Philosophy, 102, 437-457.

Hieronymi, P. (2006). Controlling attitudes. Pacific Philosophical Quarterly, 87, 45-74.

Hieronymi, P. (2008). Responsibility for believing. Synthese, 161, 357-373.

Hieronymi, P. (2009). Believing at will. Canadian Journal of Philosophy, Supplementary, 35, 149-187.

Hieronymi, P. (ms). Minds that matter, unpublished manuscript.

Hookway, C. (2002). Epistemic norms and theoretical deliberation. Ratio, 12, 380-397.

James, W. (1896). The will to believe. In The will to believe: And other essays in popular philosophy, and human immortality. Dover Publishing, 1956, pp. 1-31.

Kauppinen, A. (2018). Epistemic norms and epistemic accountability. Philosopher's Imprint, 18, 1-16.

Kavka, G. S. (1983). The toxin puzzle. Analysis, 43, 33-36. 
Kelly, T. (2002). The rationality of belief and some other propositional attitudes. Philosophical Studies, $110,163-196$.

Kiesewetter, B. (2015). Instrumental normativity: In defense of the transmission principle. Ethics, 125, 921-946.

Kiesewetter, B. (2018). Contrary-to-duty scenarios, deontic dilemmas, and transmission principles. Ethics, 129, 98-115.

Kim, B., \& McGrath, M. (2019). Pragmatic encroachment in epistemology. Routledge.

Leary, S. (2017). In defense of practical reasons for belief. Australasian Journal of Philosophy, 95, $529-542$.

Lindner, M. (2020). Implications of the debate on doxastic voluntarism for Clifford's ethics of belief. In S. Schmidt \& G. Ernst (Eds.), The ethics of belief and beyond (pp. 23-46). Routledge.

McCormick, M. S. (2015). Believing against the evidence. Routledge.

McCormick, M. S. (2018). Responding to skepticism about doxastic agency. Erkenntnis, 83, 627-645.

McCormick, M. S. (2020). Can beliefs be based on practical reasons? In A. J. Carter \& P. Bondy (Eds.), Well-founded belief (pp. 215-234). Routledge.

Meiland, J. W. (1980). What ought we to believe? Or the ethics of belief revisited. American Philosophical Quarterly, 17, 15-24.

Mele, A. R. (1997). Agency and mental action. Philosophical Perspectives, 11, 231-249.

Mitova, V. (2010). Why W. K. Clifford was a closet pragmatist. Philosophical Papers, 37, 471-489.

Parfit, D. (2011). On what matters (Vol. I). Oxford University Press.

Pascal, B. (1670). Penseés. Pacific Publishing Studios.

Pojman, L. P. (1985). Believing and willing. Canadian Journal of Philosophy, 15, 37-56.

Price, H. H. (1954). Belief and will. Proceedings of the Aristotelian Society, Supplementary Volumes, 28, 1-26.

Raz, J. (2011). From normativity to responsibility. Oxford University Press.

Reisner, A. (2008). Weighing pragmatic and evidential reasons for belief. Philosophical Studies, 138, $17-27$.

Reisner, A. (2009). The possibility of pragmatic reasons for belief and the wrong kind of reasons problem. Philosophical Studies, 145, 257-272.

Reisner, A. (2018). Pragmatic reasons for belief. In D. Star (Ed.), The Oxford handbook of reasons and normativity (pp. 705-726). Oxford University Press.

Rinard, S. (2015). Against the new evidentialists. Philosophical Issues, 25, 208-223.

Rinard, S. (2017). No exception for belief. Philosophy and Phenomenological Research, 94, 121-143.

Rinard, S. (2019a). Equal treatment for belief. Philosophical Studies, 176, 1923-1950.

Rinard, S. (2019b). Believing for practical reasons. Nous, 53, 763-784.

Schmidt, S. (2016). Können wir uns entscheiden, etwas zu glauben? Zur Möglichkeit und Unmöglichkeit eines doxastischen Willens. Grazer Philosophische Studien, 93, 571-581.

Schmidt, S. (2017). Why we should promote irrationality. Grazer Philosophische Studien, 94, 605-615.

Schmidt, S. (2020). Responsibility for attitudes, object-given reasons, and blame. In S. Schmidt \& G. Ernst (Eds.), The ethics of belief and beyond (pp. 149-175). Routledge.

Schmidt, S. (2021). Epistemic blame and the normativity of evidence. Erkenntnis. https://doi.org/10. 1007/s10670-021-00430-9

Schroeder, M. (2007). Slaves of the passions. Oxford University Press.

Schroeder, M. (2021). Reasons first. Oxford University Press.

Setiya, K. (2013). Epistemic agency: Some doubts. Philosophical. Issues, 23, 179-198.

Shah, N. (2003). How truth governs belief. Philosophical Review, 112, 447-482.

Shah, N. (2006). A new argument for evidentialism. Philosophical Quarterly, 56, 481-498.

Stich, S. (1990). The fragmentation of reason: Preface to a pragmatic theory of cognitive evaluation. MIT Press.

Stroud, S. (2006). Epistemic partiality in friendship. Ethics, 116, 498-524.

Way, J., \& Whiting, D. (2016). Reasons and guidance (or surprise parties and ice cream). Analytic Philosophy, 57, 214-235.

Worsnip, A. (2020). Can pragmatists be moderate? Philosophy and Phenomenological Research. https:// doi.org/10.1111/phpr.12673

Publisher's Note Springer Nature remains neutral with regard to jurisdictional claims in published maps and institutional affiliations. 